\title{
The transcription factor STAT5 drives mutation and imatinib resistance in chronic myeloid leukemia via ROS production
}

\author{
Eva Grundschober, Wolfgang Warsch, Veronika Sexl
}

From 17th Scientific Symposium of the Austrian Pharmacological Society (APHAR). Joint meeting with the Hungarian Society of Experimental and Clinical Pharmacology (MFT)

Innsbruck, Austria. 29-30 September 2011

\section{Background}

Chronic myelogenous leukemia (CML) is a leukemic stem cell (LSC)-driven myeloproliferative disorder and is associated with a characteristic chromosomal translocation which generates a constitutively active tyrosine kinase, the BCR-ABL oncoprotein. The standard treatment therapy for CML patients is the BCR-ABL tyrosine kinase inhibitor (TKI) imatinib. It is a life-long treatment due to the fact that LSCs are resistant to TKIs. Since its introduction, imatinib has improved the 5-year survival rate up to $90 \%$. An emerging problem is resistance to imatinib, which is mainly caused by mutations inside the BCR-ABL kinase domain, and its increasing incidence during disease progression. It has been reported that BCR-ABL drives its own mutation via upregulation of reactive oxygen species (ROS) causing oxidative DNA damage. Among the several dozens of intensively characterized mediators of BCR-ABL action, the transcription factor STAT5 is among the few ones that is critical for leukemia initiation and maintenance and it has been shown that STAT5 becomes upregulated during disease progression.

\section{Methods and results}

qPCR analysis of primary CML patient samples reveal a positive correlation of STAT5 mRNA levels and BCRABL mutations. Using BCR-ABL transformed murine cell lines retrovirally overexpressing STAT5A or STAT5B, we can show that STAT5 triggers ROS production leading to an increase in DNA double-strand breaks.

\footnotetext{
* Correspondence: veronika.sexl@vetmeduni.ac.at Institute of Pharmacology and Toxicology, Veterinary University of Vienna, 1210 Vienna, Austria
}

\section{Conclusions}

We hypothesize that STAT5 is an important mediator of imatinib resistance in CML due to its ability to drive ROS production consequently leading to $\mathrm{BCR}-\mathrm{ABL}$ mutations.

Published: 5 September 2011

doi:10.1186/1471-2210-11-S2-A22

Cite this article as: Grundschober et al:: The transcription factor STAT5 drives mutation and imatinib resistance in chronic myeloid leukemia via ROS production. BMC Pharmacology 2011 11(Suppl 2):A22.
Submit your next manuscript to BioMed Central and take full advantage of:

- Convenient online submission

- Thorough peer review

- No space constraints or color figure charges

- Immediate publication on acceptance

- Inclusion in PubMed, CAS, Scopus and Google Scholar

- Research which is freely available for redistribution

\section{() Biomed Central}

\section{Biomed Central}

